\title{
Carbohydrate Metabolism During Treatment with Chlorthalidone and Ethacrynic Acid
}

\author{
O. ORTVED ANDERSEN,* M.D.; I. PERSSON,* M.D.
}

Brit. med. F., 1968, 2, 798-801

Wilkins (1959), Finnerty (1959), and Freis (1959) were the first to report that treatment with thiazide preparations may affect the carbohydrate metabolism, and perhaps also provoke diabetes mellitus in patients who had not previously suffered from this disorder. In consideration of the widespread use of modern diuretics it is of importance to know how often such a diabetogenic effect may occur.

Chlorthalidone (Hygroton) has proved to be suitable for use in the treatment of hypertension and oedema. However, there have been reports of the occurrence of diabetes mellitus, even of fatal cases, when this compound has been used (Morét, 1965).

The effect of ethacrynic acid (Edecrin) on carbohydrate metabolism during long-term therapy has not previously been fully investigated. Because of the extent to which this diuretic is now used it would seem that a closer investigation of this problem should be made.

In order to assess the effect of the two drugs on carbohydrate metabolism patients with hypertension were investigated, before and after treatment with these preparations, by means of a number of tests for estimating such metabolism.

\section{Material and Methods}

The effect of ethacrynic acid on carbohydrate metabolism was investigated in 15 patients ( 9 women and 6 men), while that of chlorthalidone was investigated in 16 patients (11 women and 5 men). The first three patients (Cases 1-3) were treated first with chlorthalidone and then with ethacrynic acid; the next nine were treated with the diuretics in the reverse order, while the remainder received only one or other of the drugs.

All the patients suffered from mild to moderately severe essential hypertension; none had experienced cerebral vascular attacks, cerebral apoplexy, or head injury. Ten were adiposethat is, their weight exceeded the normal by more than $10 \%$. All had normal renal function, as assessed by investigation of the urine for protein, microscopy of urine, serum creatinine level, and creatinine clearance. Three had a familial disposition to diabetes mellitus, but otherwise none showed evidence of endocrine disorders or of diseases of the liver or pancreas.

The patients who were treated with chlorthalidone were aged 45 to 70 years, average 59 years. The total dosages ranged from 6.7 to $43 \mathrm{~g}$., with an average of 14.9 g., over courses of treatment lasting between 62 and 288 days, average 114 days. Those who were treated with ethacrynic acid were aged from 45 to 66 years, average 59 years. The total dosage varied from 1.9 to $13.1 \mathrm{~g}$, average $5.8 \mathrm{~g}$, and the duration of treatment ranged from 42 to 168 days, average 90 days. During the period of treatment none of the patients received other drugs that are known to affect carbohydrate metabolism. All patients received potassium chloride supplements.

Before and during treatment with chlorthalidone and ethacrynic acid the patients underwent the following investiga-

\footnotetext{
* Medical Department E. and Central Clinical Laboratory, Frederiksberg Hospital, Copenhagen, Denmark.
}

tions: oral glucose tolerance test, glucose-cortisone tolerance test, and tolbutamide test. In addition, checks were made of blood pressure and serum creatinine, potassium, sodium, chloride, and bicarbonate concentrations. In none of the patients was there any distortion of electrolyte concentrations beyond the normal range. The blood sugar concentration was estimated by duplicate determinations on ear blood with the ferricyanide method in an autoanalyser (Hoffman, 1937).

The oral glucose tolerance test was carried out with $1 \mathrm{~g}$. of dehydrated glucose per kilogram of body weight, maximum $70 \mathrm{~g}$. It was considered to be normal if the blood sugar concentration was less than $130 \mathrm{mg} . / 100 \mathrm{ml}$. two hours after administration of the glucose (limits given by Andersen and Friis, 1967).

The glucose-cortisone tolerance test was carried out in the same way as the oral glucose tolerance test after the oral administration of $50 \mathrm{mg}$. of cortisone acetate eight hours, and $50 \mathrm{mg}$. two hours, before administration of the glucose. The result was regarded as normal if the blood sugar concentration two hours after the administration of glucose did not exceed $150 \mathrm{mg} . / 100 \mathrm{ml}$. (limits stated by Andersen and Friis, 1967).

The tolbutamide test (Unger and Madison, 1958) was carried out with the patient fasting, $1 \mathrm{~g}$. of sodium tolbutamide being given intravenously over two minutes. The blood sugar concentration was determined immediately before the administration of tolbutamide and 20,30,60, and 90 minutes later. The results were considered normal if the fall in blood sugar concentration 20 minutes after the injection of tolbutamide was greater than $20 \%$ of the original value, or if the fall in blood sugar concentration reached its minimum at 30 minutes. Where the fall in blood sugar after 20 minutes was less than $20 \%$ of the initial level the test was considered to be slightly abnormal if the blood sugar concentration reached its minimum after 60 minutes, and as severely abnormal if the minimum was not reached within 90 minutes (limits stated by Andersen and Friis, 1967).

\section{Results}

It is apparent from Tables I and II that there was little correlation between the results of glucose tolerance, glucosecortisone tolerance, and tolbutamide tests.

Treatment with Ethacrynic Acid (Table I ; Figs. 1, 2, and 3.)-During treatment with ethacrynic acid the glucose tolerance test returned to normal in two patients, who had normal tolbutamide tests both before and after treatment. The two patients similarly had normal glucose-cortisone tolerance before treatment, but this became abnormal in one of them. In two patients with primarily abnormal glucose tolerance, glucose-cortisone tolerance, and tolbutamide tests these results remained abnormal, but no deterioration was observed. Two out of 11 patients who originally had normal glucose tolerance tests developed abnormal glucose tolerance; one of these two also developed an abnormal glucose-cortisone tolerance. The second patient had an abnormal glucose-cortisone tolerance, which did not deteriorate during treatment. No abnormal tolbutamide test developed in any patient. Thus during treatment with ethacrynic acid a deterioration in more than one of 
the tests used was found in only one patient (Case 2). The deterioration in the glucose tolerance test in this patient proved to be reversible during subsequent treatment with chlorthalidone.

Treatment with Chlorthalidone (Table II ; Figs. 4, 5 and 6). -During treatment with chlorthalidone the glucose tolerance returned to normal in two out of five patients. One of these had a normal tolbutamide test both before and after treatment, while in the other the tolbutamide test returned to normal. Both patients had abnormal glucose-cortisone tolerance before and after treatment. In two patients (Cases 6 and 16) deterioration was observed in both glucose tolerance and glucosecortisone tolerance, while the tolbutamide test remained unchanged during treatment. After the conclusion of treatment the reduction in tolerance was found to be reversible in one of the patients. One out of 11 patients developed an abnormal glucose tolerance; this patient had a normal tolbutamide test throughout, while the glucose-cortisone tolerance was unchanged. In one patient (Case 8) glucose-cortisone tolerance and tolbutamide tests were abnormal during the treatment. The glucose tolerance remained normal. In a further three patients tolbutamide tests were abnormal without there being any simultaneous deterioration in either glucose or glucose-cortisone tolerance. Thus during treatment with chlorthalidone there was deterioration in more than one of the tests used in three patients.

Statistical Evaluation.-For the statistical evaluation of the difference in the changes in glucose tolerance in the 12 patients who were treated with both drugs the binomial distribution expressed as the positive or negative difference in glucose tolerance in the same patient has been used. Comparison of the maximum values for glucose tolerance in the two groups showed a significant difference with a $p$ value of 0.039 . With the
Student's $t$-test no aggravation of statistical signifiance was observed in any of the tests when the two drugs were administered.

\section{Discussion}

A number of reports have hitherto been published on the injurious effect of various diuretics on carbohydrate metabolism. It has, for example, been stated that up to $25 \%$ of patients treated with benzothiadiazine develop diabetes (Wolff et al., 1963), as compared with $15 \%$ of the normal population.

However, only in a few cases have these findings been the subject of closer investigation; as a rule only the blood sugar or the urinary sugar content was investigated before treatment was started. Shapiro et al. (1961), however, investigated 15 "potential" diabetics and 15 normal patients before and after treatment with chlorthalidone, using the glucose tolerance test. They found a reduction in carbohydrate tolerance in the disposed patients, but none in the control group. Similarly, Jahnecke (1967), using the glucose tolerance test, investigated the effect of chlorthalidone on the carbohydrate metabolism, and found no significant deterioration in the curves. However, he excluded patients in whom the glucose tolerance test taken before treatment suggested the presence of latent diabetes mellitus. Jackson and Nellen (1966) are the only workers who have carried out comparative studies of two compounds-namely, frusemide and chlorothiazide-in the same group of patients. They found no evidence of deterioration in either glucose tolerance test or tolbutamide test in any of the 19 patients investigated.

The cause of the deterioration in carbohydrate metabolism has not been elucidated. It would seem that hypokalaemia (Rapoport and Hurd, 1954), injury to the pancreas (Cornish et al., 1961), and formation of insulin antibodies (Greenberg

TABLE I.-Carbohydrate Tolerance Tests on Ethacrynic Acid

\begin{tabular}{|c|c|c|c|c|c|c|c|c|c|c|c|c|c|c|}
\hline \multirow{3}{*}{$\begin{array}{l}\text { Case } \\
\text { No. }\end{array}$} & \multirow{3}{*}{ Sex } & \multirow{3}{*}{ Age } & \multicolumn{2}{|c|}{ Glucose Tolerance Test } & \multicolumn{2}{|c|}{ Cortisone Tolerance Test } & \multirow{2}{*}{\multicolumn{4}{|c|}{$\begin{array}{c}\text { Tolbutamide } \\
\text { Test* }\end{array}$}} & \multirow{3}{*}{$\begin{array}{c}\text { Duration } \\
\text { of } \\
\text { Treatment } \\
\text { in Days }\end{array}$} & \multirow{3}{*}{ Obesity } & \multirow{3}{*}{$\begin{array}{l}\text { Dys- } \\
\text { pnoea }\end{array}$} & \multirow{3}{*}{$\begin{array}{c}\text { Total } \\
\text { Ethacrynic } \\
\text { Acid } \\
\text { Dose (g.) }\end{array}$} \\
\hline & & & $\underset{\text { Before }}{\text { Max. } / 2 \text { hours }}$ & $\mid \begin{array}{c}\text { Max. } / 2 \text { hours } \\
\text { After }\end{array}$ & $\underset{\text { Before }}{\text { Max. } / 2 \text { hours }}$ & $\mid \begin{array}{c}\text { Max./2 hours } \\
\text { After }\end{array}$ & & & & & & & & \\
\hline & & & \multicolumn{4}{|c|}{ mg. $/ 100 \mathrm{ml}$. } & \multicolumn{2}{|c|}{ Before } & \multicolumn{2}{|c|}{ After } & & & & \\
\hline $\begin{array}{r}1 \\
2 \\
3 \\
4 \\
5 \\
6 \\
7 \\
8 \\
9 \\
10 \\
11 \\
12 \\
13 \\
14 \\
15\end{array}$ & $\begin{array}{l}\mathbf{F} \\
\mathbf{F} \\
\mathbf{F} \\
\mathbf{F} \\
\mathbf{M} \\
\mathbf{F} \\
\mathbf{M} \\
\mathbf{M} \\
\mathbf{M} \\
\mathbf{M} \\
\mathbf{F} \\
\mathbf{F} \\
\mathbf{P} \\
\mathbf{F}\end{array}$ & $\begin{array}{l}45 \\
51 \\
63 \\
56 \\
57 \\
59 \\
60 \\
63 \\
65 \\
65 \\
66 \\
66 \\
47 \\
59 \\
66\end{array}$ & $\begin{array}{l}253 / 128 \\
193 / 95 \\
183 / 112 \\
165 / 86 \\
181 / 147 \\
243 / 185 \\
246 / 124 \\
212 / 117 \\
200 / 132 \\
254 / 112 \\
191 / 190 \\
200 / 105 \\
192 / 85 \\
167 / 90 \\
180 / 113\end{array}$ & $\begin{array}{l}221 / 129 \\
195 / 139 \\
160 / 110 \\
228 / 67 \\
190 / 114 \\
216 / 187 \\
178 / 65 \\
180 / 120 \\
167 / 105 \\
214 / 126 \\
205 / 204 \\
200 / 141 \\
202 / 72 \\
147 / 117 \\
200 / 96\end{array}$ & $\begin{array}{l}255 / 198 \\
220 / 139 \\
254 / 154 \\
235 / 97 \\
213 / 130 \\
290 / 247 \\
290 / 180 \\
198 / 161 \\
224 / 146 \\
265 / 145 \\
227 / 235 \\
270 / 185 \\
217 / 51 \\
180 / 106 \\
228 / 146\end{array}$ & $\begin{array}{l}260 / 144 \\
245 / 162 \\
253 / 192 \\
242 / 98 \\
205 / 75 \\
253 / 208 \\
290 / 84 \\
186 / 110 \\
240 / 173 \\
253 / 172 \\
240 / 202 \\
223 / 177 \\
209 / 84 \\
175 / 149 \\
198 / 107\end{array}$ & $\begin{array}{l}\mathrm{N} \\
\mathrm{LA} \\
\mathrm{N} \\
\mathbf{N} \\
\mathrm{HA} \\
\mathrm{LA} \\
\mathbf{N} \\
\mathbf{N} \\
\mathrm{LA} \\
\mathrm{HA} \\
\mathbf{N} \\
\mathbf{N} \\
\mathbf{N}\end{array}$ & $\begin{array}{l}65 \\
81 \\
69 \\
74 \\
93 \\
86 \\
77 \\
76 \\
90 \\
86 \\
78 \\
83 \\
73 \\
79\end{array}$ & $\begin{array}{l}\mathbf{N} \\
\mathbf{N} \\
\mathbf{N} \\
\mathbf{N} \\
\mathbf{N} \\
\mathbf{L A} \\
\mathbf{N} \\
\mathbf{N} \\
\mathbf{N} \\
\mathbf{L A} \\
\mathbf{L} \\
\mathbf{N} \\
\mathbf{N} \\
\mathbf{N}\end{array}$ & $\begin{array}{l}74 \\
84 \\
74 \\
67 \\
75 \\
89 \\
71 \\
72 \\
72 \\
80 \\
80 \\
73 \\
79 \\
63 \\
69\end{array}$ & $\begin{array}{r}123 \\
168 \\
126 \\
87 \\
98 \\
63 \\
42 \\
74 \\
129 \\
112 \\
84 \\
63 \\
42 \\
91 \\
49\end{array}$ & $\begin{array}{l}\overline{-} \\
\pm \\
+ \\
+ \\
\pm \\
+ \\
\pm \\
\pm \\
\pm \\
\overline{+} \\
\bar{t}\end{array}$ & $\begin{array}{l}= \\
\pm \\
\pm \\
\pm \\
= \\
= \\
= \\
= \\
=\end{array}$ & $\begin{array}{r}9.2 \\
13.1 \\
3.9 \\
6.3 \\
6.4 \\
2.1 \\
1.9 \\
10.1 \\
6.1 \\
5.5 \\
5.6 \\
5.6 \\
3.9 \\
4.2 \\
2.6\end{array}$ \\
\hline
\end{tabular}

* Tolbutamide Test: $\mathbf{N}=$ normal; $\mathrm{LA}=$ slightly abnormal; $\mathrm{HA}=$ severely abnormal. Values indicate concentration of blood sugar 20 minutes after administration of tolbutamide as percentage of initial value.

TABLE II.-Carbohydrate Tolerance Tests on Chlorthalidone

\begin{tabular}{|c|c|c|c|c|c|c|c|c|c|c|c|c|c|c|}
\hline \multirow{3}{*}{$\begin{array}{l}\text { Case } \\
\text { No. }\end{array}$} & \multirow{3}{*}{ Sex } & \multirow{3}{*}{ Age } & \multicolumn{2}{|c|}{ Glucose Tolerance Test } & \multicolumn{2}{|c|}{ Cortisone Tolerance Test } & \multirow{2}{*}{\multicolumn{4}{|c|}{$\begin{array}{c}\text { Tolbutamide } \\
\text { Test* }\end{array}$}} & \multirow{3}{*}{$\begin{array}{c}\text { Duration } \\
\text { of } \\
\text { Treatment } \\
\text { in Days }\end{array}$} & \multirow{3}{*}{ Obesity } & \multirow{3}{*}{$\begin{array}{c}\text { Dys- } \\
\text { pnoea }\end{array}$} & \multirow{3}{*}{$\begin{array}{l}\text { Total } \\
\text { Chlortha- } \\
\text { lidone } \\
\text { Dose (g.) }\end{array}$} \\
\hline & & & Max. $/ 2$ hours & Max. $/ 2$ hours & Max. $/ 2$ hours & Max./2 hours & & & & & & & & \\
\hline & & & \multicolumn{4}{|c|}{$\mathrm{mg} . / 100 \mathrm{ml}$. } & \multicolumn{2}{|c|}{ Before } & \multicolumn{2}{|c|}{ After } & & & & \\
\hline $\begin{array}{r}1 \\
2 \\
3 \\
4 \\
5 \\
6 \\
7 \\
8 \\
9 \\
10 \\
11 \\
12 \\
16 \\
17 \\
18 \\
19\end{array}$ & $\begin{array}{l}\mathrm{F} \\
\mathbf{F} \\
\mathbf{F} \\
\mathrm{F} \\
\mathbf{M} \\
\mathbf{F} \\
\mathbf{M} \\
\mathbf{M} \\
\mathbf{M} \\
\mathbf{M} \\
\mathbf{F} \\
\mathbf{F} \\
\mathbf{F} \\
\mathbf{F} \\
\mathbf{F} \\
\mathbf{F}\end{array}$ & $\begin{array}{l}45 \\
51 \\
63 \\
56 \\
57 \\
59 \\
60 \\
63 \\
65 \\
66 \\
66 \\
66 \\
47 \\
51 \\
63 \\
70\end{array}$ & $\begin{array}{l}202 / 155 \\
168 / 120 \\
177 / 115 \\
228 / 67 \\
190 / 114 \\
216 / 187 \\
178 / 65 \\
180 / 120 \\
168 / 105 \\
214 / 126 \\
205 / 204 \\
200 / 141 \\
170 / 105 \\
189 / 76 \\
249 / 114 \\
248 / 245\end{array}$ & $\begin{array}{l}197 / 114 \\
193 / 95 \\
183 / 112 \\
205 / 102 \\
220 / 102 \\
256 / 237 \\
233 / 99 \\
205 / 124 \\
185 / 129 \\
245 / 115 \\
234 / 165 \\
164 / 85 \\
158 / 119 \\
160 / 111 \\
202 / 132 \\
367 / 367\end{array}$ & $\begin{array}{l}252 / 153 \\
247 / 154 \\
226 / 188 \\
242 / 98 \\
205 / 75 \\
253 / 208 \\
290 / 84 \\
188 / 110 \\
241 / 173 \\
253 / 172 \\
240 / 202 \\
223 / 176 \\
205 / 105 \\
217 / 128 \\
270 / 211 \\
280 / 280\end{array}$ & $\begin{array}{l}265 / 166 \\
222 / 139 \\
254 / 154 \\
193 / 89 \\
205 / 130 \\
277 / 250 \\
280 / 125 \\
228 / 154 \\
233 / 181 \\
245 / 104 \\
272 / 212 \\
237 / 182 \\
188 / 113 \\
215 / 112 \\
252 / 203 \\
378 / 378\end{array}$ & $\begin{array}{l}\text { LA } \\
L A \\
\text { LA } \\
N \\
N \\
\text { LA } \\
N \\
N \\
N \\
N \\
\text { LA } \\
N \\
N \\
\text { LA } \\
N \\
\text { HA }\end{array}$ & $\begin{array}{l}89 \\
80 \\
83 \\
67 \\
75 \\
89 \\
71 \\
72 \\
72 \\
80 \\
80 \\
73 \\
67 \\
85 \\
61 \\
89\end{array}$ & $\begin{array}{l}\mathbf{N} \\
\mathrm{LA} \\
\mathbf{N} \\
\mathrm{LA} \\
\mathrm{LA} \\
\mathrm{LA} \\
\mathrm{HA} \\
\mathbf{N} \\
\mathrm{LA} \\
\mathbf{N} \\
\mathbf{N} \\
\mathbf{N} \\
\mathbf{N} \\
\mathrm{HA}\end{array}$ & $\begin{array}{l}70 \\
81 \\
67 \\
91 \\
90 \\
81 \\
90 \\
79 \\
90 \\
72 \\
74 \\
79 \\
75 \\
82\end{array}$ & $\begin{array}{r}67 \\
67 \\
129 \\
87 \\
96 \\
173 \\
187 \\
62 \\
102 \\
84 \\
83 \\
103 \\
105 \\
288 \\
88 \\
101\end{array}$ & $\begin{array}{l}\overline{ } \\
+ \\
+ \\
+ \\
\pm \\
\pm \\
\pm \\
\pm \\
\pm \\
= \\
\overline{+} \\
+\end{array}$ & $\begin{array}{l}\bar{z} \\
\pm \\
\pm \\
\pm \\
= \\
= \\
= \\
= \\
= \\
=\end{array}$ & $\begin{array}{r}6.7 \\
6 \cdot 7 \\
12.9 \\
8.7 \\
13.8 \\
22.5 \\
26.8 \\
10.4 \\
14.2 \\
8.4 \\
14 \cdot 3 \\
10.3 \\
20.2 \\
43.0 \\
8 \cdot .8 \\
10.2\end{array}$ \\
\hline
\end{tabular}

- Tolbutamide Test: $\mathrm{N}=$ normal; LA = slightly abnormal; HA = severely abnormal. Values indicate concentration of blood sugar 20 minutes after administration of tolbutamide as percentage of initial value. 
et al., 1962) are not the precipitating causes. Animal experiments with diazoxide, which is known to cause diabetes in man (Dollery et al., 1962), have shown a decrease in the glycogen content of the liver (Tabachnick et al., 1964). The administration of diazoxide to pancreatomized dogs caused an increase in the already raised blood sugar. It must therefore be concluded that the cause of the diabetogenic effect of the diuretic drugs is most probably a glycogenolysis, possibly mediated by adrenergic compounds.

In the evaluation of the diabetogenic effect of any diuretic drug it is necessary to bear in mind that many of the patients who are treated with these drugs are hypertensive, elderly, and adipose. It is known that in such patients (Kramer, 1928 ; Newburgh et al., 1938 ; Heimsoth and Hartmann, 1965) the incidence of diabetes mellitus, even in the absence of diuretic therapy, is higher than that in normotensive younger persons of normal weight. The incidence of manifest and latent diabetes in these patients has been shown to be $32 \%$ and $29 \%$ respectively. The question of the reproducibility of the tolerartce curves is of fundamental importance in evaluation of the results. However, Jackson (1964) has shown that these are generally reproducible in the individual patient. In the present study some of the patients were investigated several times after the conclusion of treatment, and the results were similar for each patient. It has, moreover, been shown that dehydration of patients may cause the tests for diabetes mellitus to return to normal. However, this cannot explain the improvement observed in some of those investigated. With the reservations necessarily associated with the small number of cases observed our investigations involving the long-term treatment of hypertensive patients, about half of whom were adipose, with ethacrynic acid in therapeutic doses resulted in no change or an
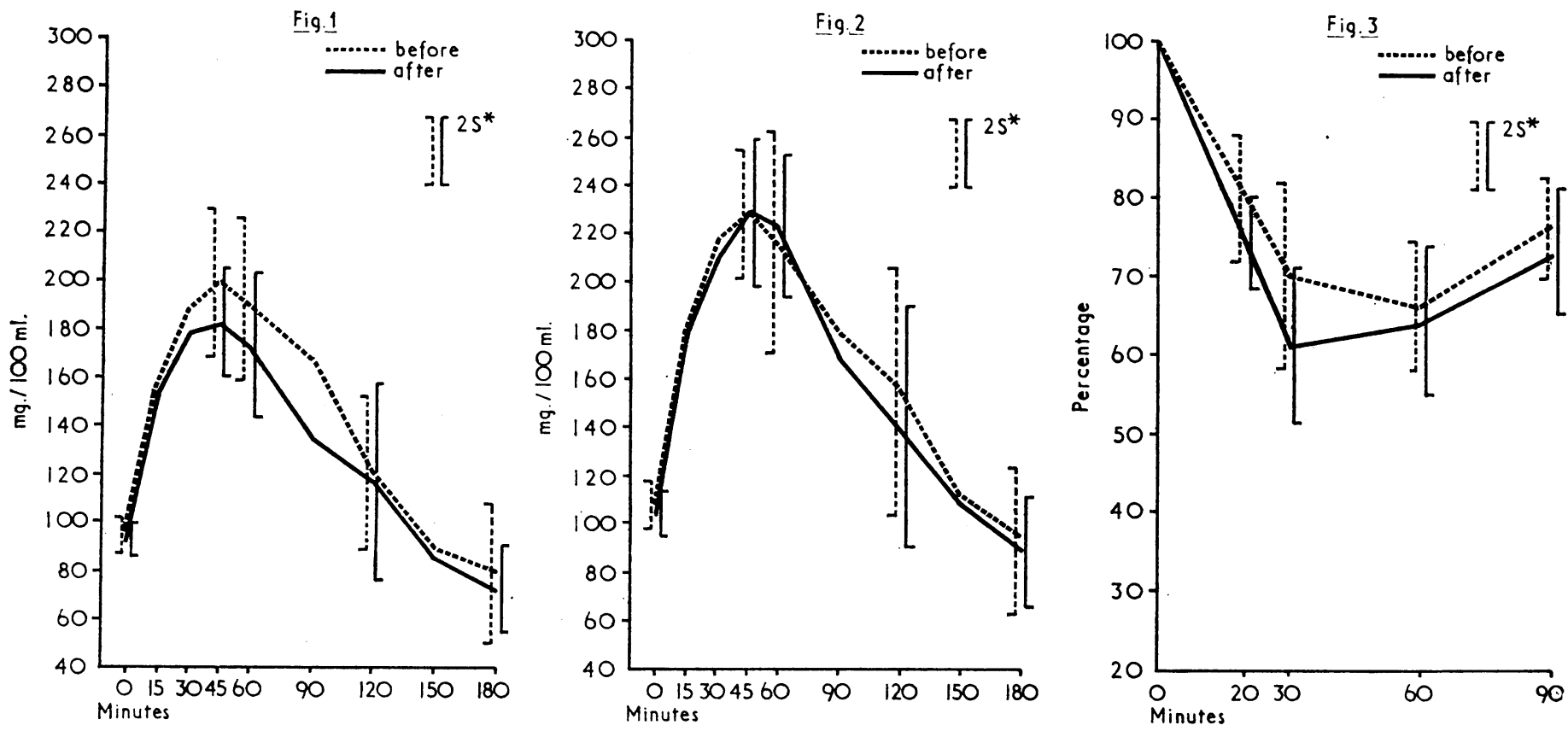

FIG. 1.-Ethacrynic acid. Glucose tolerance test in 15 patients. $S^{*}=$ Standard deviation. Fig. 2.-Ethacrynic acid. Cortisone tolerance test in 15 patients. FIG. 3.-Ethacrynic acid. Tolbutamide test in 14 patients.
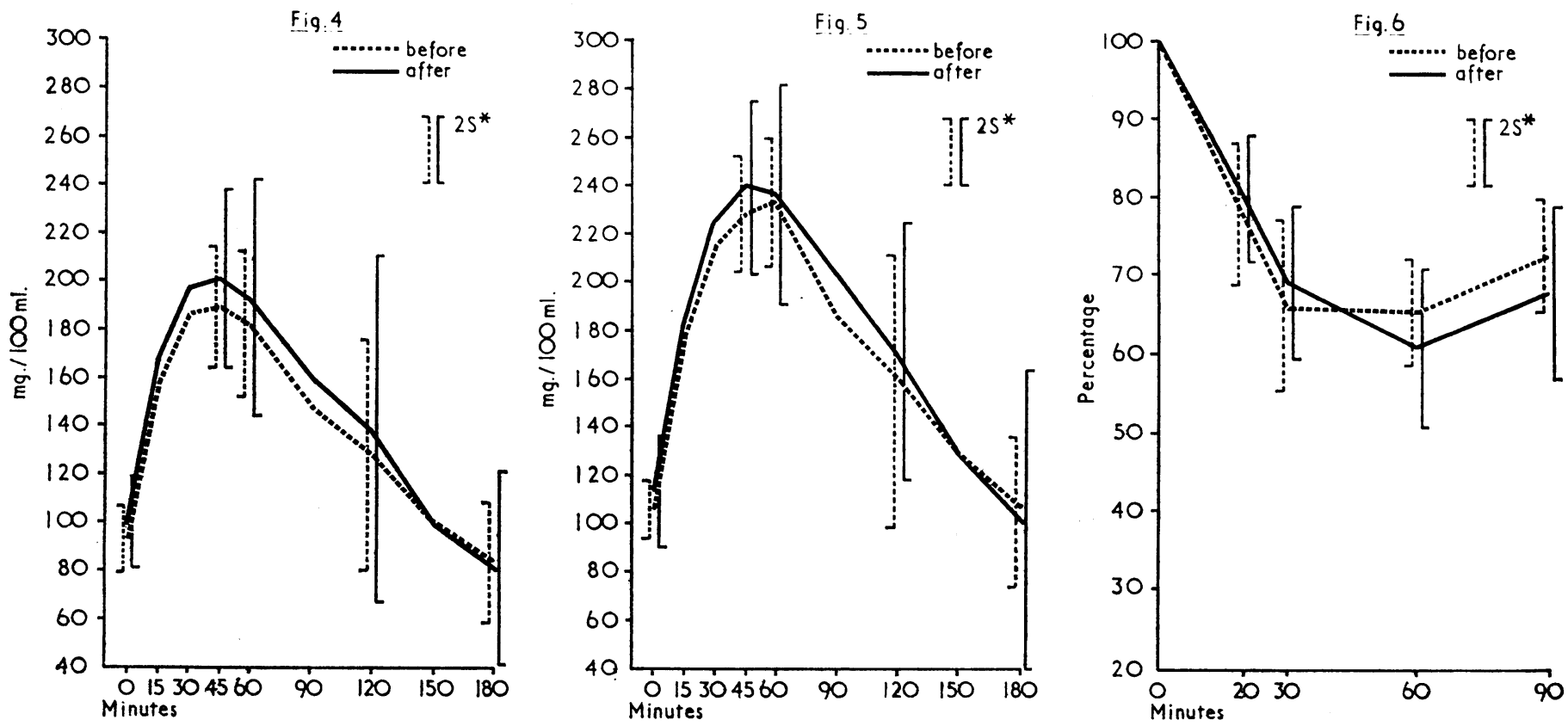

Fig. 4.-Chlorthalidone. Glucose tolerance test in 16 patients. Fig. 5.-Chlorthalidone. Cortisone tolerance test in 16 patients. Fig. 6.Chlorthalidone. Tolbutamide test in 14 patients. 
improvement in the results of the glucose tolerance test in 14 out of 15 patients $(93 \%)$. There was a reversible reduction of tolerance in only one patient.

During long-term treatment with chlorthalidone in therapeutic doses the glucose tolerance was found to be unchanged in 10 out of the 16 patients $(55 \%)$. In three patients there was only slightly reduced tolerance, while in the remaining three there was severely reduced tolerance, which on follow-up was found to be irreversible in two cases and reversible in the third. The marked reduction in tolerance was found principally in patients in whom the original investigations had shown obviously diabetic glucose and glucose-cortisone tolerance, but it was not found only in the patients who had the longest duration of treatment.

Though the two groups of patients were not identical in all respects, it must be emphasized that 12 of them were treated with the two diuretics alternately. Where glucose tolerance was concerned the two groups were comparable. In order to avoid deterioration in latent diabetes mellitus it would seem practicable to determine the two-hour value in the glucose tolerance test. Increased values in this test indicate a necessity for caution in the use of diuretics, particularly chlorthalidone.

\section{Summary}

The administration of ethacrynic acid to 15 patients suffering from essential hypertension resulted in one case of reversible reduction of carbohydrate tolerance. In a similar trial one out of 16 patients who received chlorthalidone developed diabetes mellitus and two others had a considerably reduced carbohydrate tolerance, which in one case was irreversible. Latent diabetes should be taken as an indication for special care in the use of diuretics, especially chlorthalidone.

\section{REFERENCES}

Andersen, O. O., and Friis, T. (1967). Acta med. scand., 181, 535.

Andersen, . O., and Friis, T. (1967). New Engl. 7. Med., 265, 673.

Dollery, C. T., Pentecost, B. L., and Samaan, N. A. (1962). Lancet, 2, 735.

Finnerty, F. A. (1959). In Hypertension : First Hahnemann Symposium on Hypertensive Disease, edited by J. H. Moyer, p. 653. Philadelphia.

Freis, E. D. (1959). In Hypertension : First Hahnemann Symposium on Hypertensive Disease, edited by J. H. Moyer, p. 545. Philadelphia.

Greenberg, S., Dresner, M., and Gorczyga, R. (1962). Amer. F. med. Sci., 67, 710 .

Heimsoth, V., and Hartmann, F. (1965). Dtsch. med. Wschr., 90, 1467.

Hoffman, W.'S. (1937). 7. biol. Chem., 120, 51 .

Jackson, W. P. U. (1964). On Diabetes Mellitus. Springfield, Illinois.

Jackson, W. P. U., and Nellen, M. (1966). Brit. med. Y., 2, 333.

Jahnecke, J. (1967). Dtsch. med. W schr., 92, 1270.

Kramer, D. W. (1928). Amer. F. med. Sci., 176, 23.

Morét, B. (1965). Dtsch. med. W schr., $90,1136$.

Newburgh, L. H., Conn, J. W., Johnston, M. W., and Conn, E. S. (1938). Trans. Ass. Amer. Phycns, 53, 245.

Rapoport, M. I., and Hurd, H. F.'(1964). Arch. intern. Med., 113, 405.

Rapoport, M. 1., and Hurd, H. F. (1964). Arch. intern. Med. Mew Engl. $₹$. Shapiro, A. P., Benedek, T. G., and Small, J. L. (1961). New Engl. F. Med., 265, 1028.

Tabachnick, I. I. A., Gulbenkian, A., and Seidman, F. (1964). Diabetes, 13, 408 .

Unger, R. H., and Madison, L. L. (1958). Diabetes, 7, 455.

Wilkins, R. W. (1959). Ann. intern. Med., 50, 1.

Wolff, F. W., Parmley, W. W., White, K., and Ókun, R. (1963). 7. Amer. ined. Ass., 185, 568.

\section{Lysergide and Chromosome Abnormalities}

\section{J. NIELSEN,* M.D. ; U. FRIEDRICH,* M.D. ; E. JACOBSEN,* M.D. ; T. TSUBOI,* M.D.}

Brit. $\underline{\text { med. F., 1968, 2, 801-803 }}$

Studies by Cohen et al. (1967), Irwin and Egozcue (1967), and Zellweger et al. (1967) have shown an increased frequency of chromosome breaks in patients treated with lysergide. Court Brown (1968b) emphasizes the necessity of having controls and of defining the chromosome abnormalities described when studying chromosome abnormalities in patients exposed to drugs or radiation.

\section{Material and Methods}

Chromosomes were studied on leucocytes cultured 48 or 72 hours ; 48 hours for the five patients treated with lysergide and for half of the controls. The chromosome analysis was made on film projections in a magnification of approximately 6,000 in combination with analysis in a Zeiss photomicroscope. All aneuploid cells and at least 15 cells with a modal figure were analysed. All cells were, however, analysed for gaps, breaks, and other chromosome abnormalities. Gaps are defined as achromatic lesions with no dislocation, while one of the two chromatid parts are dislocated in breaks. Examples of chromatid as well as of isochromatid gaps and breaks are seen in Fig. 1.

We studied five patients aged 29-48 who had been given from 2,200 to $17,500 \mu \mathrm{g}$. of lysergide, with the highest single doses varying from 50 to $300 \mu \mathrm{g}$. and with 6 to 38 months between the last lysergide treatment and the chromosome analysis. Table I shows the distribution of the five lysergide-treated

\footnotetext{
* Cytogenetic Laboratory, Aarhus State Hospital, Risskov, Denmark.
}

patients according to age, sex, lysergide treatment, gaps, breaks, and hyperdiploid cells. Four of the five (Cases 2-5) suffered from neurosis with obsessional traits and had been given lysergide as part of their treatment. None of the five had been exposed to radiation. We also studied 40 controls none of whom had taken lysergide, 30 of them being patients in a psychiatric hospital and 10 being chosen from the personnel in this hospital.

\section{Results}

The results of the study are shown in Table II and Figs. 1, 2 , and 3. We found 12 chromatid gaps and 45 isochromatid gaps, giving a total of 57 gaps in 358 cells in the five lysergidetreated patients $(15.9 \%)$. There were 53 chromatid gaps and

TABLE I.-Lysergide-treated Patients

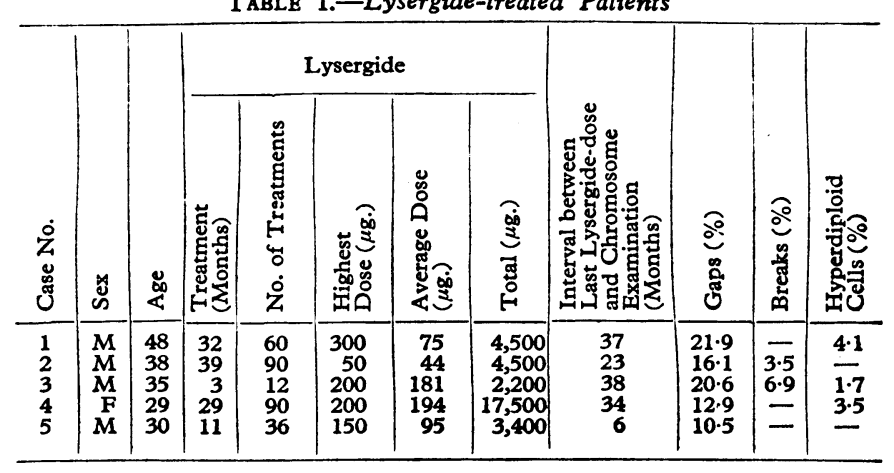

